\section{Intraosseous (IO) access in neonate with birth weight 2300 gr in cardiorespiratory arrest, a challenge in pre-hospital emergency care}

Alonso Sánchez, María del Mar RN; Rey Paterna, Paloma RN; Galán Caletegui María Dolores, RN; de Lucas Nieves, MD Pediatrician

\section{Background}

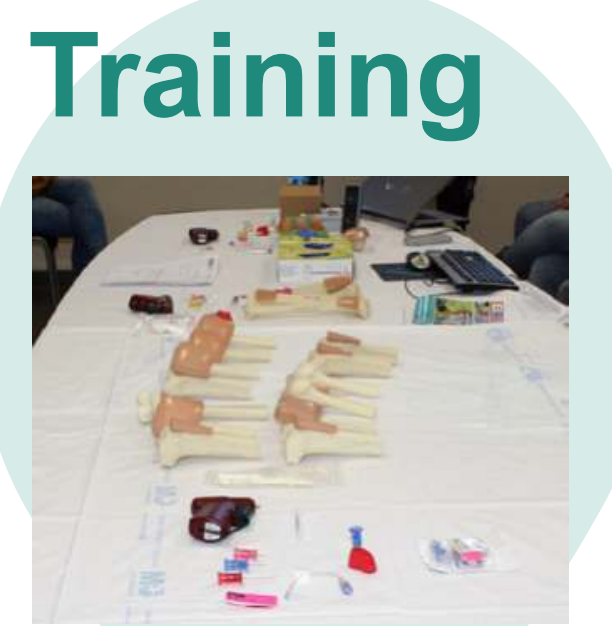

Initial Trauma Care SAMUR EZ-IO Workshops

\section{Experience}

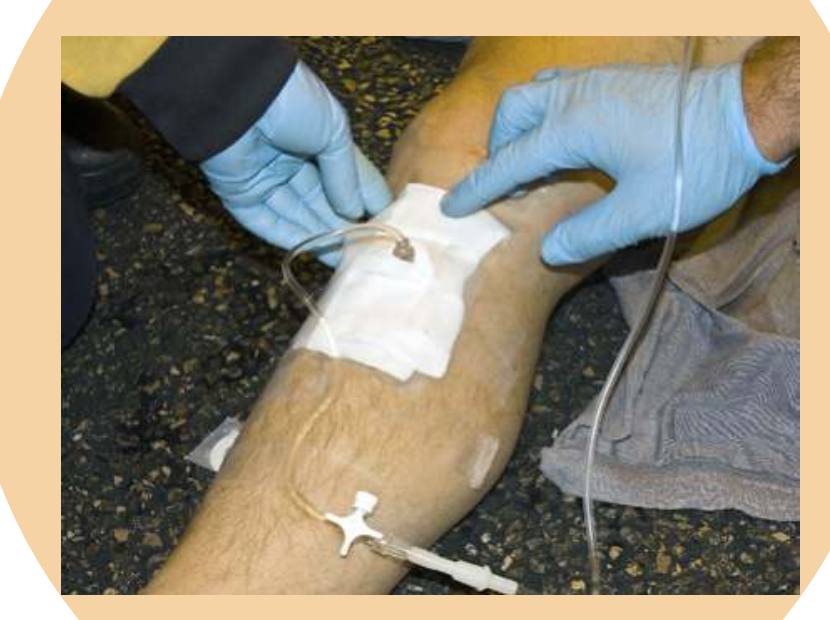

More than 300 cases registered up to 2015

\section{Incidence}

11,883 critically ill patients

up to 3 years old: $\mathbf{8 4}$

up to 1 year old: $\mathbf{3 1}$

2007-2017

SAMUR - Protección Civil

\section{Endorsed by}

Manual of Procedures

SAMUR - Protección Civil

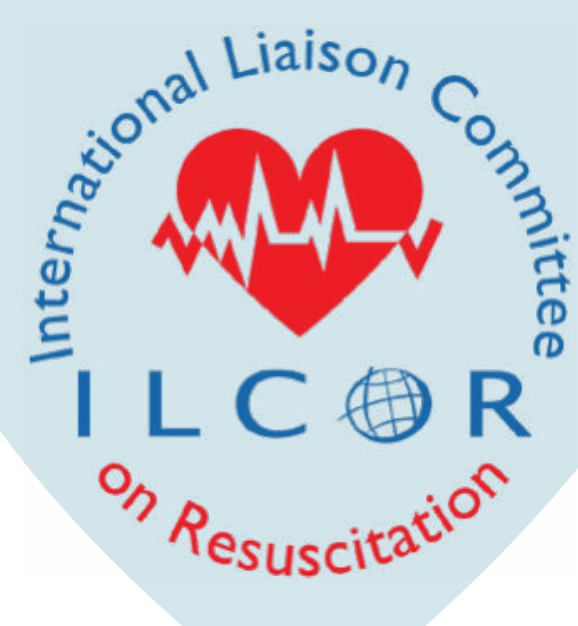

Use of the intraosseous route in a premature infant (Arch Pediatr 1998)

Nasimi A, Gorin P, Berthier M, Boussemart T, Follet-Bouhamed C, Oriot D

- Toulouse neonatal resuscitation unit. 34-week-old pre-term neonate.

$2200 \mathrm{gr}$ (14 days of life).

- Septic shock.

Subclavian catheter was pulled out 10 access $(20 \mathrm{G}$, distal hole, Cook) - Left in place for 14 hours to infuse antibiotics, inotropic support, blood products and colloids.
Intraosseous (IO) access in neonate with birth weight 2300 gr

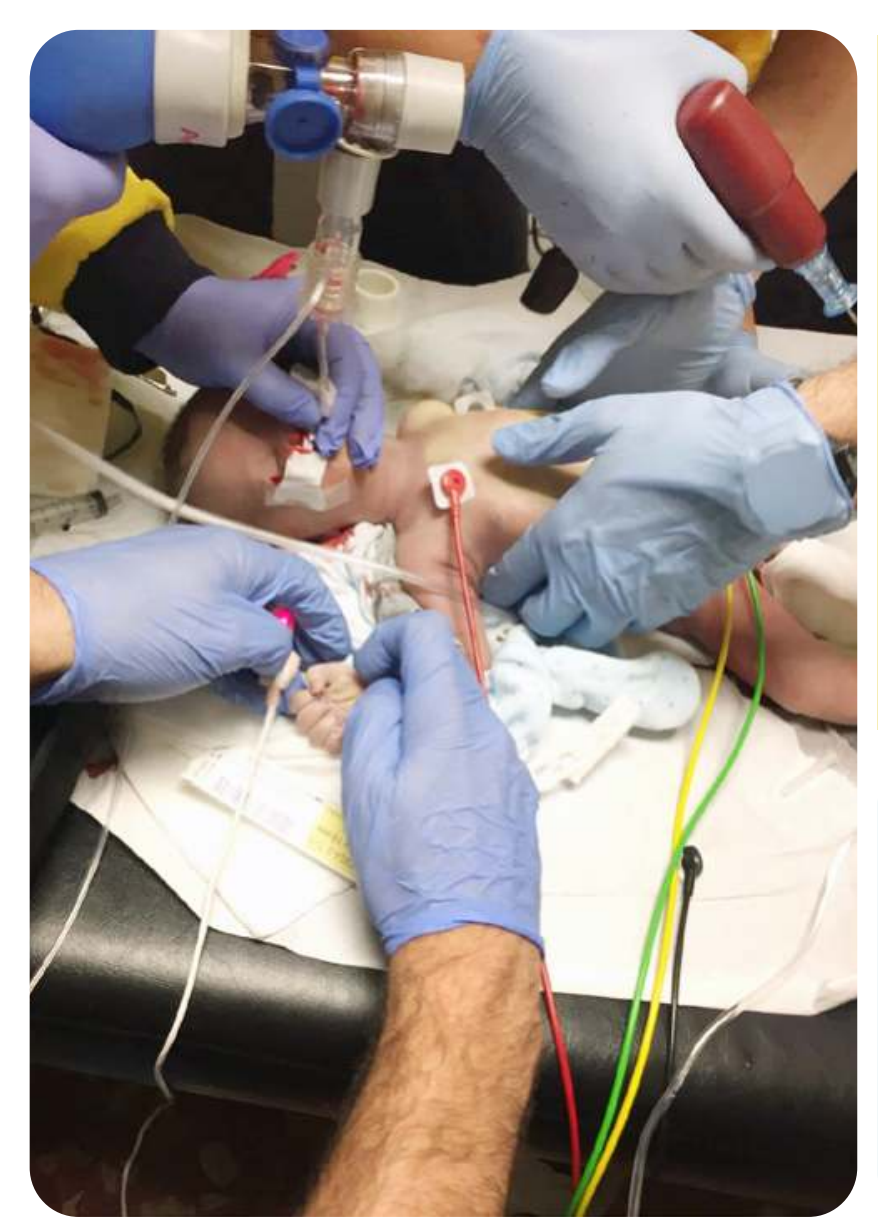

Neonate weighing 2300 grams at birth after 37 weeks of pregnancy

One-week old

- Cardiac arrest

Central cianosis despite of mechanical ventilation

Vomit containing milk and blood

Primary Health Care facility.

Instrumental CPR

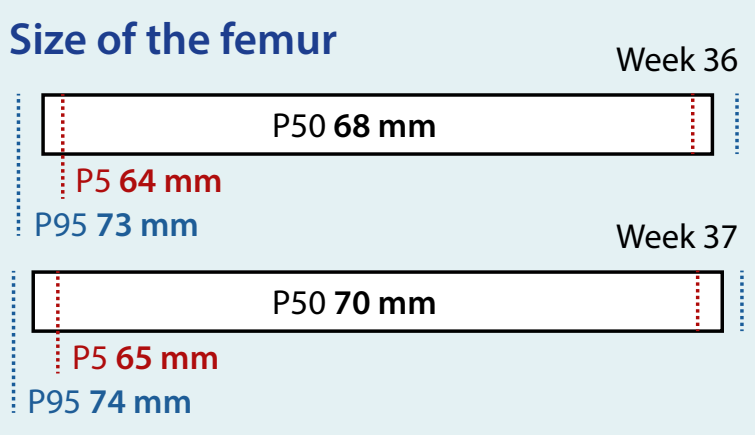

2 failed attempts to obtain an intraosseous tibial access

Causes: - Low density bones

- Vibrations during CPR maneuvres

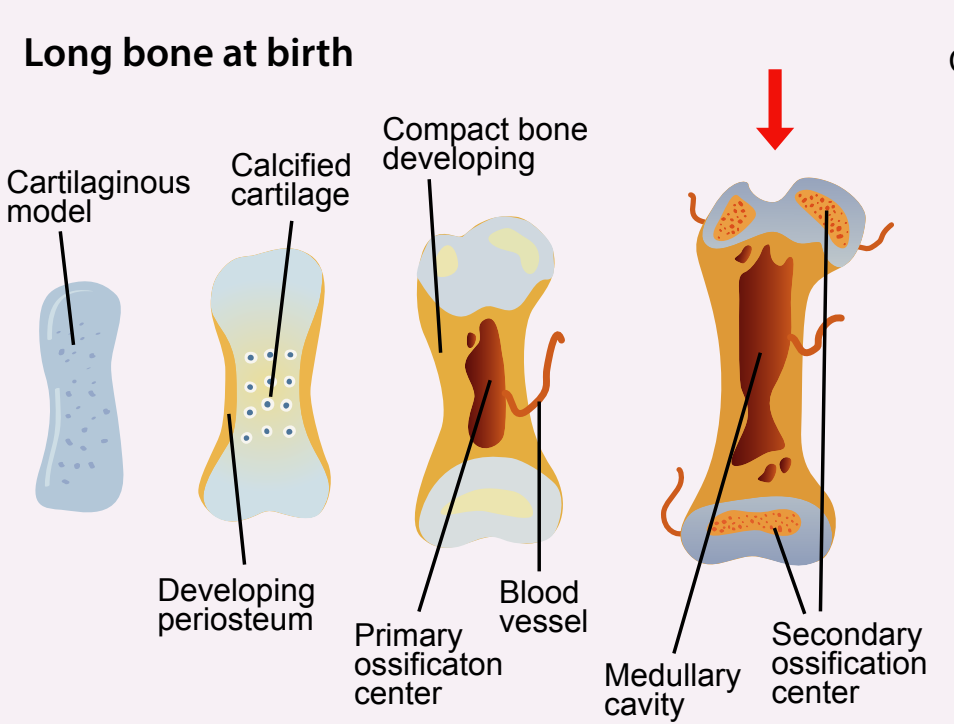

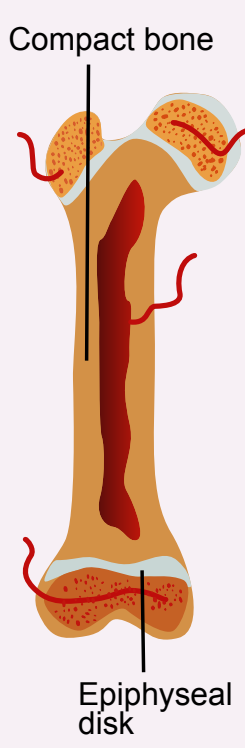

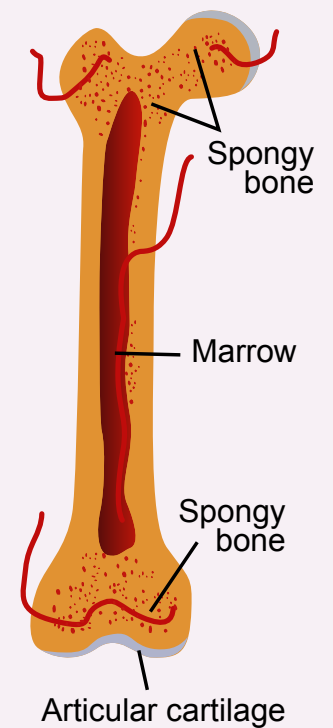

\section{Femoral IO Access}

Left in place for 50 minutes

Drugs infused: adrenaline, sodium bicarbonate, glucose (glycemia : $12 \mathrm{mg} / \mathrm{dl}=0,666 \mathrm{mmol} / \mathrm{l}$ )

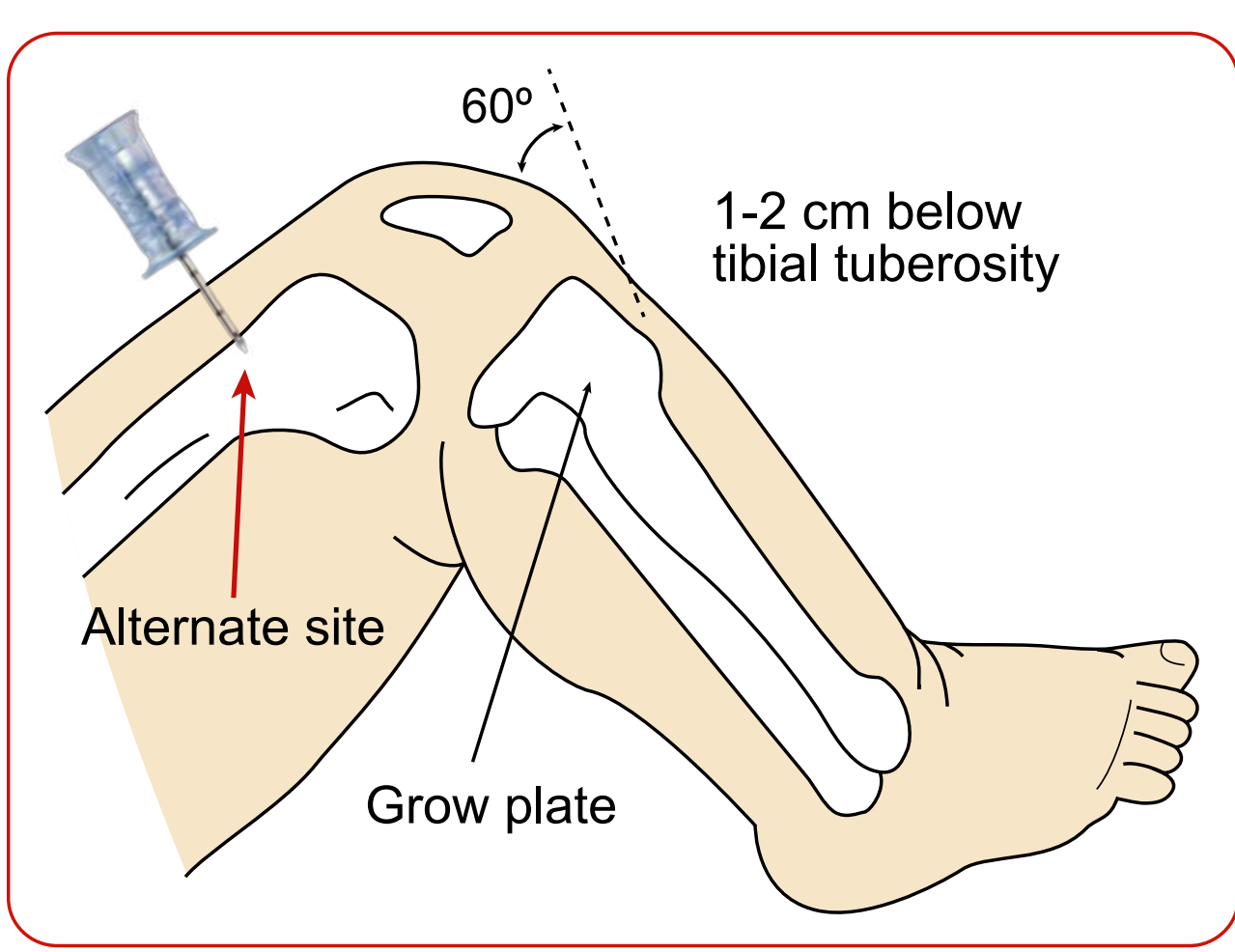

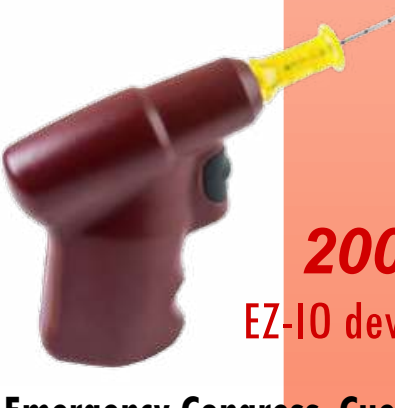

Emergency Congress, Cuence Nurse evaluation of a new device
for insertion of Intraosseous route SES Congress, Tarragona SEMES Congress, Tarragona
Surey about the use of the intraosseous rey about the use of the intraosseeus
route in the prehospital setting
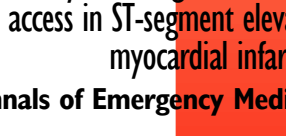

2012

SEMES Congress, Oviedo Intransseous route in severet trauma: four
vears of experience in SAMUR-Protección Civi'

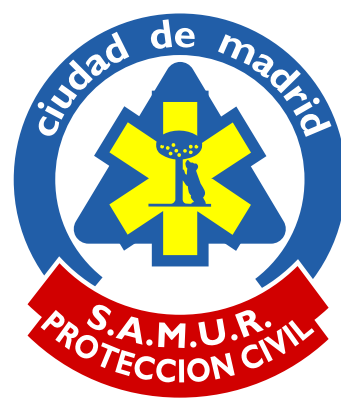

Conclusion

In premature an low-weight critically ill infants, the use of the intraosseous route should be considered as the first option

SEMES Cong IO device is safe and fast as long as the profesional has training on it.

In premature and low-weight infants, distal femur should be considered better than proximal tibial access. DELTA team: senior nurses supporting and sharing experience with nurses on duty. 